\title{
Assistência ao surdo na atenção primária: concepções de profissionais
}

Assistance to deaf in primary health care: conceptions of professionals Asistencia a los sordos en la atención primaria: concepciones profesionales

Rosângela Nunes Almeida da Silva; ${ }^{1}$ Sernandes Rodrigues da Silva ${ }^{2}$; Francidalma Soares Sousa Carvalho Filha ${ }^{3}$; Francisco Laurindo da Silva ${ }^{4}$; Jaiane de Melo Vilanova ${ }^{5}$

\section{Resumo}

A surdez é a incapacidade de um indivíduo ouvir perfeitamente. Assim, a pessoa surda encontra várias barreiras no atendimento ao procurar os serviços de saúde na Atenção Primária à Saúde. O objetivo deste estudo foi avaliar a assistência ofertada aos surdos na Atenção Primária à Saúde na concepção de profissionais de saúde. Trata-se de uma pesquisa avaliativa por triangulação de métodos, com abordagem quanti-qualitativa, realizado nas Unidades Básicas de Saúde do município de Caxias, Maranhão, com 99 profissionais de saúde. Verificaram-se que os profissionais atuantes na Atenção Primária não dominam e por isso não utilizam a Libras na assistência ao surdo. A comunicação é a principal barreira que há entre surdos e profissionais, que impede a compreensão, e assim, a realização de uma boa assistência. A Atenção Primária do município não tem nenhum tipo de recurso, quer seja ele físico, material ou organizacional para auxiliar os profissionais no atendimento à pessoa surda. Há uma necessidade urgente de os profissionais fazerem capacitações em Libras para melhor atender aos usuários surdos.

Descritores: Atenção Primária à Saúde, Profissionais de Saúde, Surdez.

\footnotetext{
Abstract

Deafness is the inability of an individual to hear perfectly. Thus, the deaf person found several barriers to care seeking health services in primary health care. The aim of this study was to evaluate the assistance offered to the deaf at the primary health care in the design of health professionals. It is an evaluation research by triangulation methods, with quantitative and qualitative approach, carried out in Basic Health Units in the city of Caxias, Maranhão, with 99 health professionals. They found that professionals working in primary care do not dominate and therefore do not use the

${ }^{1}$ Mestranda em Biodiversidade, Ambiente e Saúde pela Universidade Estadual do Maranhão (UEMA). Enfermeira da Atenção Primária em Saúde de Aldeias Altas-MA e docente do curso de Enfermagem, na Universidade Estadual do Maranhão. Secretaria Municipal de Saúde, Avenida João Rosa, 285, Centro, Aldeias Altas, Maranhão, Brasil. CEP: 65610-000. E-mail: rnadasilva@ hotmail.com

${ }^{2}$ Acadêmico de Enfermagem pela Faculdade de Ciências e Tecnologia do Maranhão (FACEMA). Rua Aarão Reis. 1000, Centro, Caxias, Maranhão, Brasil. CEP: 65606-020. E-mail: rnadasilva1@ @mail.com

${ }^{3}$ Mestre em Enfermagem pela Universidade Federal do Piauí (UFPI). Docente do curso de Enfermagem, na Faculdade de Ciências e Tecnologia do Maranhão (FACEMA) e na Universidade Estadual do Maranhão (UEMA). Faculdade de Ciências e Tecnologia do Maranhão, Rua Aarão Reis. 1000, Centro, Caxias, Maranhão, Brasil. CEP: 65606-020. Email: francidalmafilha@gamil.com

${ }^{4}$ Doutor em Ciências Biológicas (Microbiologia) pela Universidade Federal de Minas Gerais (UFMG). Docente do curso de Enfermagem, na Faculdade de Ciências e Tecnologia do Maranhão (FACEMA) e na Universidade Estadual do Maranhão (UEMA). Universidade Estadual do Maranhão, Centro de Estudos Superiores de Caxias, Morro do Alecrim, S/N, Caxias, Maranhão, Brasil. CEP: 65600-000. E-mail: flspb@yahoo.com.br

${ }^{5}$ Especialista em Saúde da Família pela Fundação Gianna Beretta. Enfermeira da Estratégia Saúde da Família em Balsas-MA. Rua Professora Joca Rego, 121, Centro, Balsas, Maranhão, Brasil. CEP: 65800-000. E-mail: jai_vilanova@hotmail.com
} 
ISSN 2179-6750

Pounds in assisting the deaf. Communication is the main barrier that exists between deaf and professionals that prevents understanding, and thus the achievement of good care. The Primary of the municipality does not have any type of resource, whether it is physical, material or organization to assist professionals in healthcare for deaf people. There is an urgent need for professional training in Libras do to better serve deaf users.

Key-words: Primary Health Care, Health professionals, Deafness.

\section{Resumen}

La sordera es la incapacidad de un individuo para oír perfectamente. Por lo tanto, la persona sorda encontró varias barreras a la atención de salud en busca de servicios de atención primaria de salud. El objetivo de este estudio fue evaluar la asistencia que se ofrece a los sordos en la atención primaria de salud en el diseño de los profesionales de la salud. Se trata de una encuesta de evaluación por métodos de triangulación con enfoque cuantitativo y cualitativo, realizado en las Unidades Básicas de Salud en la ciudad de Caxias, Maranhão, con 99 profesionales de la salud. Encontraron que los profesionales que trabajan en atención primaria no dominan y por lo tanto no utilice libras en la asistencia a los sordos. La comunicación es la principal barrera que existe entre sordos y profesionales que impide la comprensión, y por lo tanto el logro de un buen recorrido. La Primaria del municipio no tiene ningún tipo de recurso, ya sea física, material o de organización para ayudar a los profesionales en la atención sanitaria a las personas sordas. Hay una necesidad urgente de profesionales para hacer formación en Libras para servir mejor a los usuarios sordos.

Palabras-claves: Atención primaria de salud, Profesionales de la salud, La sordera.

\section{Introdução}

A audição é um dos sentidos mais importantes e é essencial para a aquisição da linguagem falada, por isso, a surdez traz muitas limitações para o desenvolvimento do indivíduo e influencia no relacionamento da mãe e/ou de outros familiares e amigos com o surdo, além de estabelecer lacunas nos processos psicológicos de integração de experiências, afetando, inclusive, o equilíbrio e a capacidade normal de desenvolvimento da pessoa ${ }^{1}$.

A deficiência auditiva ou surdez é a perda da audição bilateral, parcial ou total, de quarenta e um decibéis $(\mathrm{dB})$ ou mais, aferida por audiograma nas frequências de $500 \mathrm{HZ}, 2.000 \mathrm{HZ}$ e $3.000 \mathrm{HZ}$ 2

É fato que o ser humano tem necessidade de se comunicar com o mundo que está externo ao seu corpo. Por isso, realiza-se no compreender e ser compreendido, como também nas interações interpessoais. A comunicação e a interação com o mundo à sua volta, são necessidades que independem da vontade do ser humano.

Neste sentido, o surdo deseja ser tão entendido quanto o ouvinte, mas na maioria das vezes não pode se comunicar por igual porque não consegue ouvir, o que o impede de desenvolver a fala, que é a forma mais usada de expressão. O censo aponta que 6,7\% da população brasileira tem alguma deficiência severa e a auditiva atinge cifras em torno de $1,1 \%$ do público citado ${ }^{3}$. 
ISSN 2179-6750

Ao se realizar comparações entre as pessoas com deficiência física, auditiva e visual, o surdo é o que enfrenta maior dificuldade de inclusão na sociedade, porquanto a audição é o sentido essencial para a aquisição e uso da linguagem, além da efetivação da comunicação entre os seres humanos ${ }^{4}$.

Somado a este problema, a maioria dos profissionais de saúde não sabe usar a Língua Brasileira de Sinais (LIBRAS) e não está suficientemente preparado para cuidar da pessoa surda, o que dificulta, quando não impede e/ou prejudica o acesso da pessoa portadora de deficiência auditiva aos serviços públicos ou privados de saúde a que tem direito, como todos os cidadãos brasileiros, conforme assegurado pela Constituição Federal de $1988^{5}$.

A LIBRAS é a segunda língua oficial do Brasil. Foi legalizada pela Lei Federal nº 10.436/02 e regulamentada pelo Decreto $\mathrm{n}^{\mathrm{o}} 5.626$ de 22 de dezembro de 2005 e, desde então, tem sido difundida nos mais variados setores sociais, educacionais e de saúde, embora ainda desconhecida na maioria das instâncias ${ }^{6}$.

A este respeito, é conveniente ressaltar que o capítulo VII do Decreto de Lei $n^{\circ} 5.626$, de 22 de dezembro de 2005, que trata da garantia do direito à saúde das pessoas surdas, determinou que, a partir de 2006, o atendimento a estas pessoas na rede de serviços do Sistema Único de Saúde (SUS) bem como nas empresas que detêm concessão ou permissão de serviços públicos de assistência à saúde, seja realizado por profissionais capacitados para o uso de LIBRAS ou para a sua tradução e interpretação.

Por este motivo, desde que a LIBRAS foi reconhecida oficialmente e com base na referida lei, iniciaram-se cobranças da sociedade civil organizada para que os profissionais e instituições de saúde se preparassem para assistir mais adequada e efetivamente a população surda, embora muito pouco ou quase nada tenham obtido êxito, no sentido de resguardar os direitos à saúde e à dignidade dessas pessoas ${ }^{7}$.

Ademais, enfatiza-se que o direito de viver dignamente não pode ser removido de alguém por lhe faltar algum órgão ou sentido ou ainda, porque de qualquer outra maneira pareça ou até mesmo seja distinto do que se é comum à maioria das pessoas. Portanto, as diferenças físicas, mentais, culturais ou sociais não podem ser mais importantes do que as próprias pessoas, nem tampouco ser privados da aquisição do se expressar e viver livremente.

Independentemente de apresentar surdez, o ser humano merece ser bem atendido em todos os setores da saúde, sobretudo na Atenção Primária à Saúde (APS), por tratar-se da porta de entrada do sistema e, conforme Ohara e Saito ${ }^{8}$ considerar o sujeito em sua singularidade, complexidade, integralidade e inserção sociocultural, além de realizar a promoção de sua saúde, a prevenção e 
ISSN 2179-6750

tratamento de doenças e a redução de danos ou de sofrimentos que possam comprometer suas possibilidades de viver de modo saudável e autônomo.

Assim, a atenção que os profissionais atuantes na Estratégia Saúde da Família (SF) prestam aos usuários deve resolver ou, pelo menos, amenizar a maioria dos problemas de saúde, de maneira tal que trabalhadores de saúde e usuários interajam em uma relação que se estimule a vinculação e a conquista da liberdade de expressão e humanização do atendimento. Por isso, estes trabalhadores em saúde podem e devem ser munidos de todo o conhecimento necessário para atender às necessidades de saúde dos sujeitos assistidos e melhorar os resultados obtidos no atendimento.

De acordo com estimativas, no município de Caxias, Maranhão, existem cerca de 1.705 surdos ${ }^{3}$. Este dado exige uma reflexão por parte dos gestores em saúde, educadores, profissionais de saúde em geral e dos próprios surdos, acerca da assistência que, de fato, é ofertada nos serviços de saúde deste município, pois esta é uma quantidade muito grande de pessoas, muitas vezes ignoradas, que precisam ter pleno acesso aos cuidados de saúde, com base nos princípios da Universalidade, Integralidade e Equidade do SUS.

Com base nisso, esta pesquisa poderá trazer aos profissionais de saúde e gestores uma noção da realidade vivenciada pelos usuários quando da necessidade dos serviços de saúde e aos próprios surdos uma esperança de que algo está sendo feito ou pelo menos, planejado para incentivar a implantação e/ou efetivação de um atendimento digno ou, em última instância, fomentará o debate e análise de problemas oriundos do desconhecimento acerca desta temática.

Além disso, trará à tona a discussão de que todas as pessoas, não importa a cultura, raça, credo ou se apresentam deficiências, têm direitos que precisam ser preservados. Possibilitará também, aos profissionais de saúde, uma avaliação de suas competências e condutas frente aos surdos, estimulando a melhora em suas práticas de atendimento aos mesmos.

Reitera-se que um trabalho desta magnitude, revelará em seu conteúdo uma preocupação significativa com a problemática em questão, uma vez que, como assegura ${ }^{9}$, as discussões acerca desta temática ainda têm se mostrado insuficientes, quando não incipientes. Por isso, nitidamente, os gritos de quem não se comunica através da fala quase não são ouvidos, nem é dada importância alguma às suas necessidades.

Assim, o objetivo deste estudo foi avaliar a assistência ofertada aos surdos na Atenção Primária à Saúde na concepção de profissionais de saúde. 


\section{Metodologia}

Trata-se de uma pesquisa avaliativa sob três aspectos: avaliação de conformidade (ou normativa), com abordagem quanti-qualitativa, onde foram analisadas as ações desenvolvidas na APS, voltadas aos usuários surdos, com base no que está preconizado nos documentos legais acerca da temática e também foi feita uma análise da percepção de profissionais de saúde que prestam a assistência ao surdo. A avaliação por triangulação de métodos pretende ir além das duas formas mais clássicas de abordagem, a positivista e a compreensiva, e processa-se por meio do diálogo de diferentes métodos e técnicas e amplia as contribuições teórico-metodológicas, de modo a perceber movimentos, estruturas, ações dos sujeitos, indicadores e relações entre realidades ${ }^{10}$. Ademais, de acordo com ${ }^{11}$, a articulação entre abordagens e combinações metodológicas tem reconhecida importância para pesquisar o complexo saúde-doença-atenção, indicando as diversas modalidades de diálogos. Nesse contexto, o quantitativo e o qualitativo traduzem cada um na sua definição, as conexões entre o individual e o coletivo, presentes no cotidiano das práticas de saúde.

A metodologia qualitativa foi aplicada por se adequar à investigação das percepções e das opiniões que as pessoas emitem a respeito de como vivem, sentem, pensam, constroem a si mesmas e seus artefatos ${ }^{12}$, como o fazem os profissionais da Atenção Primária à Saúde.

O cenário desta investigação foi o Município de Caxias, de área de 5.150,647 km², situado na região leste do estado do Maranhão, a 374 quilômetros da capital São Luís, e a 70 quilômetros da capital piauiense, Teresina. Apresenta uma população aproximada de 155.129 habitantes ${ }^{13}$. Segundo dados da Coordenação da APS e do Sistema de Informação da Atenção Básica (SIAB), o município está estruturado com 58 Equipes de Saúde da Família (ESF), distribuídas em 21 UBS da zona urbana e 11 UBS da zona rural. Assim, foram coletados dados em todas as unidades de saúde da zona urbana do município.

Entre os profissionais atuantes na APS, o município conta com 43 médicos, 60 enfermeiros e 58 cirurgiões dentistas, 112 auxiliares e/ou técnicos de enfermagem e 264 agentes comunitários de saúde (ACS). Portanto, solicitou-se a participação dos 537 trabalhadores, dos quais, 99 (20 médicos, 19 enfermeiros, 20 cirurgiões dentistas, 20 auxiliares/técnicos de enfermagem e 20 ACS) aceitaram participar da pesquisa.

A coleta de dados foi norteada por um formulário, aplicado aos profissionais de saúde entre os meses de janeiro a julho de 2014, nas Unidades Básicas de Saúde, em seus horários de funcionamento, em um consultório fechado para garantir a privacidade dos participantes, com duração média de 30 minutos, em horários previamente agendados com os participantes. $\mathrm{O}$ formulário é um roteiro de perguntas enunciadas pelo entrevistador e preenchidas por ele com as 
ISSN 2179-6750

respostas do pesquisado, possibilitando a elaboração de questões mais complexas, com vistas a garantir a exaustão de todas as possibilidades frente ao tema estudado ${ }^{14}$.

Os dados coletados por meio dos formulários aplicados aos profissionais de saúde foram organizados e apresentados, conforme suas especificidades em informações quantitativas, quando se referia às respostas das perguntas fechadas e qualitativas, nas abertas.

Assim, após a aplicação dos referidos instrumentos a ambos os grupos de interlocutores, compôs-se um banco de dados com as informações quantitativas, que foram digitadas no software Statistical Package for the Social Sciences - SPSS (versão 18.0 for Windows), e, posteriormente, foram consolidadas por meio das técnicas de estatísticas descritivas (frequências absoluta e relativa) e apresentadas sob a forma de tabelas. Procedeu-se a discussão dos achados com base na literatura produzida sobre o tema.

Ademais, para não se perder a essência das respostas dos profissionais de saúde em relação ao atendimento ofertado aos surdos, suas argumentações mais importantes foram dispostas na apresentação dos resultados, por meio de recortes de suas falas, com a identificação da sigla referente a cada categoria profissional, seguida da numeração de 1 a 20 , pela ordem em que os formulários foram aplicados. Assim, os médicos foram apresentados como M1-20; os enfermeiros como E1-19; os cirurgiões dentistas como CD1-20; os auxiliares/técnicos de enfermagem como AT1-20 e os agentes comunitários de saúde como ACS1-20. O mesmo processo foi realizado em relação aos surdos, em que as informações referentes à assistência recebida por eles na APS foram demonstradas em falas, a partir das descrições feitas pela intérprete de Libras.

Ressalta-se que todas as informações advindas dos questionamentos abertos aplicado aos profissionais, foram submetidas à Análise de Conteúdo, que tem como propósito a compreensão do significado das falas dos sujeitos para além dos limites daquilo que é descrito. Entre as técnicas de Análise de Conteúdo, optou-se pela Análise Temática, que busca os núcleos de sentido, os quais constituem a comunicação e cuja expressão revela algo de importante para o objeto estudado ${ }^{15}$

Portanto, de posse do material procedeu-se a categorização, inferência, descrição e interpretação minuciosa de todo o conteúdo. Para tanto, após a leitura compreensiva das falas, foi feita a exploração das mesmas, e, portanto, a análise propriamente dita, e, por fim, elaborou-se uma síntese interpretativa por meio de uma redação que proporcionasse um diálogo do tema com objetivos, questões e pressupostos da pesquisa ${ }^{16}$. Cabe destacar que conforme ${ }^{12}$, considera-se que a interpretação consiste em relacionar os significantes com os significados presentes na mensagem, removendo-se daí os núcleos de entendimento. 
ISSN 2179-6750

Quanto aos aspectos éticos, o projeto foi aprovado pelo Comitê de Ética em Pesquisa com o Certificado de Apresentação para Apreciação Ética (CAAE) no 13930813.1.0000.5554. Os pesquisadores comprometeram-se com as normas preconizadas pela Resolução CNS 466/12 e suas complementares, que tratam dos aspectos éticos da pesquisa envolvendo seres humanos e os sujeitos assinaram o Termo de Consentimento Livre e Esclarecido.

\section{Resultados e Discussão}

As tabelas e as categorias analisadas que serão descritas a seguir, referem-se aos dados coletados dos formulários aplicados a 99 profissionais de enfermagem (20 Médicos, 19 Enfermeiros, 20 Cirurgiões dentista, 20 Auxiliares/Técnicos de Enfermagem e 20 Agentes Comunitários de Saúde), atuantes na Atenção Primária à Saúde em Caxias-MA.

Dados quantitativos

A Tabela 1 versa sobre o conhecimento dos profissionais de saúde atuantes na APS, sobre à capacitação em Libras. Para isso, discute-se a respeito das categorias profissionais, enfatizando a importância da utilização da Língua Brasileira de Sinais.

Tabela 1. Distribuição de profissionais de saúde atuantes na APS, por categoria, quanto à Capacitação em LIBRAS. Caxias (MA), 2014.

\begin{tabular}{lcccccc} 
Categorias & \multicolumn{2}{c}{ Conhecimento (Não) } & \multicolumn{2}{c}{ Conhecimento (Sim) } & \multicolumn{2}{c}{ TOTAL } \\
Profissionais & $\mathbf{n}$ & $\mathbf{\%}$ & $\mathbf{n}$ & $\boldsymbol{\%}$ & $\mathbf{n}$ & $\mathbf{\%}$ \\
Médico & 19 & 95,0 & $\mathbf{1}$ & $\mathbf{5 , 0}$ & $\mathbf{2 0} \mathbf{1 0 0 , 0}$ \\
Enfermeiro & 19 & 100,0 & $\mathbf{0}$ & $\mathbf{0 , 0}$ & $\mathbf{1 9} \mathbf{1 0 0 , 0}$ \\
Cirurgião Dentista & 20 & 100,0 & $\mathbf{0}$ & $\mathbf{0 , 0}$ & $\mathbf{2 0} \mathbf{1 0 0 , 0}$ \\
Aux./Téc. Enfermagem & 19 & 95,0 & $\mathbf{1}$ & $\mathbf{5 , 0}$ & $\mathbf{2 0} \mathbf{1 0 0 , 0}$ \\
ACS & 18 & 90,0 & $\mathbf{2}$ & $\mathbf{1 0 , 0}$ & $\mathbf{2 0} \mathbf{1 0 0 , 0}$ \\
\hline TOTAL & $\mathbf{9 5}$ & $\mathbf{9 5 , 9}$ & $\mathbf{4}$ & $\mathbf{4 , 1}$ & $\mathbf{9 9} \mathbf{1 0 0 , 0}$
\end{tabular}

Conforme se observa nesta tabela, 95 (95,9\%) profissionais não estão capacitados para utilizar Libras na assistência a usuários surdos. Foram encontrados resultados semelhantes em seu estudo e afirmam que os profissionais da saúde não estão suficientemente preparados para cuidar da pessoa surda, já que a comunicação, item essencial da assistência de todo e qualquer indivíduo não está sendo efetivada ${ }^{5}$.

Em relação aos médicos, 19 (95\%) não são capacitados em Libras. Os médicos precisam conhecer a Libras, e, de acordo com os autores, antes de qualquer situação, é preciso interessar-se 
ISSN 2179-6750

pelo surdo, ser empático, tentar compreender as dificuldades encontradas, conhecer sua cultura. Sendo que esse interesse deve ser estimulado na formação acadêmica dos profissionais, por isso, a Libras começou a ser inserida na grade curricular dos cursos da área da saúde ${ }^{17}$.

Verificou-se também que nenhum dos enfermeiros tem capacitação em Libras. Destacam-se a atenção ao fato que o enfermeiro, é o profissional que mais se aproxima dos usuários, por isso, precisa comunicar-se de forma consciente com o cliente, na tentativa de decodificar, decifrar e perceber o significado da mensagem que o paciente envia; identificando suas necessidades e prestando uma assistência de enfermagem de qualidade ${ }^{18}$.

A comunicação efetiva, por meio do uso adequado das técnicas da comunicação interpessoal, é condição imprescindível para que o profissional, especialmente o enfermeiro, possa ajudar o paciente a atender suas demandas em saúde ${ }^{19}$.

Em se tratando dos cirurgiões dentistas, observou-se que, em termos de conhecimento de Libras, nenhum profissional está apto a atender os surdos pois não são capacitados para tal. A este respeito, referem que para se desenvolver o cuidado em saúde bucal, não se pode utilizar apenas os conhecimentos técnico-científicos dos profissionais, mas também são essenciais o acolhimento, a efetiva comunicação, além de observar os princípios do SUS da universalidade, integralidade e equidade da atenção ${ }^{20}$.

Isso implica dizer que os cirurgiões dentistas, assim como os demais profissionais de saúde devem conhecer a Libras, para facilitar sua comunicação com o usuário surdo, que possibilitará conhecer suas reais necessidades, favorecendo a construção de um ambiente de interação mútua e enriquecendo a assistência, que deve ser voltada para atender as necessidades e particularidades.

Com relação aos auxiliares/técnicos de enfermagem, 19 (95\%) afirmaram não ter domínio sobre a Libras. Apesar de apenas realizarem serviços técnicos, também necessitam dominar a comunicação humana, já que todo o seu trabalho será realizado com o auxílio da mesma. É dever dos profissionais buscar conhecer a Libras, para oferecer ao surdo cuidados cada vez mais humanos, dignos e eficazes. Os autores se referem a todos os profissionais de saúde, inclusive o auxiliar/técnico de enfermagem, pois, em geral, é quem recebe os usuários na UBS, marca as consultas e demais atendimentos, além de prestar o serviço de saúde de nível técnico e, por isso, precisa estabelecer uma comunicação prolongada e duradoura com todos os usuários, independentemente se têm alguma deficiência ou não ${ }^{21}$.

Quanto aos ACS, 18 (90\%) não são capacitados em Libras. Apesar do resultado negativo, observa-se que dentre as categorias, eles são os que mais conhecem a língua. Porém, mesmo tendo a maior quantidade de pessoas capacitadas, não é um número significante, tendo em vista o fato de 
ISSN 2179-6750

que todos os profissionais deveriam ser capacitados para se comunicar de maneira efetiva e prestar uma boa assistência ao usuário surdo. O ACS como o detentor do saber popular e represente do elo que há entre a população e os profissionais da UBS. Os autores corroboram a importância do profissional dominar a Libras, tendo em vista que o ACS os usuários profundamente, adentra as suas casas, desvenda suas necessidades, adquire informações sobre o cotidiano, inclusive de emprego e renda. Por isso, esse trabalhador deve manter um diálogo com todos os membros da família, para lhes repassar as informações necessárias dos serviços e ações disponíveis em sua UBS de $\operatorname{adscrição~}^{22}$.

$\mathrm{Na}$ Tabela 2 são apresentados os dados obtidos com os profissionais relativos às sugestões de implantação e/ou melhoria dos serviços de saúde com vistas a se atender mais adequadamente ao usuário surdo.

Tabela 2. Distribuição de profissionais de saúde atuantes na APS quanto às sugestões para melhorar o atendimento dos usuários surdos. Caxias (MA), 2014.

\begin{tabular}{lcr} 
Sugestões & n & $\%$ \\
Capacitações & 99 & 100,0 \\
Recursos Visuais & 76 & 76,7 \\
Cartilha em Libras & 52 & 52,5 \\
Contratação de interpretes & 31 & 31,3 \\
\hline \multicolumn{2}{c}{ Fonte: Pesquisa direta }
\end{tabular}

Conforme se observa nesta tabela, para que a realidade do atendimento ao surdo melhore, foram sugeridos pelos profissionais de saúde que sejam feitas capacitações em Libras, na abordagem e na assistência ao surdo; que sejam sintetizados e/ou adquiridos recursos visuais que auxiliem na comunicação entre clientes e trabalhadores; que sejam disponibilizadas cartilhas com sinais em Libras voltadas à saúde e ainda que sejam contratados intérpretes da Libras para acompanhar os profissionais da APS no atendimento ao usuário surdo. A comunicação entre profissionais e surdos é bastante desafiadora, necessitando de recursos humanos capacitados e materiais visuais com sinais em Libras ${ }^{23}$.

Os profissionais participantes desta pesquisa foram unânimes em discutir sobre a importância de capacitações para o atendimento ao surdo em sua língua oficial, como uma medida a ser adotada na APS, buscando ofertar uma assistência de qualidade aos usuários surdos. A este respeito ${ }^{24}$, referem que é importante o profissional de saúde ter pelo menos noções básicas de Libras para que obtenha um bom relacionamento e desenvolvimento, promovendo a orientação de um procedimento ou até mesmo na discussão de um caso clínico. 
ISSN 2179-6750

A sugestão dada por $76(76,7 \%)$ profissionais foi a obtenção ou confecção de recursos visuais que possam auxiliar no acolhimento ao surdo na UBS, fazendo com que se sinta bem e queira retornar outras vezes. Tais recursos podem ser contemplados por cartazes, folhetos, o alfabeto em Libras, carinhas expressivas de dor, alegria, raiva e preocupação, além de imagens que auxiliem na comunicação. Corroboram ${ }^{25}$, a importância do uso de recursos visuais na assistência ao surdo quando afirmam que usar a língua de sinais é falar com as mãos e ouvir com olhos.

Ainda foi sugerido por $52(52,5 \%)$ profissionais que fossem disponibilizadas cartilhas em Libras. A cartilha é um manual para consulta do profissional, onde o mesmo pudesse recorrer sempre que necessário, contendo as expressões mais utilizadas nas consultas e demais atendimentos, com seus respectivos sinais em Libras. Como apoio para a comunicação entre profissionais e usuários surdos, deve haver materiais impressos com sinais em Libras direcionados à saúde $^{23}$.

Houve ainda, a sugestão de 31 (31,3\%) dos sujeitos, quanto à contratação de profissionais capacitados para auxiliar na comunicação entre surdos e profissionais de saúde. A presença do intérprete é válida, porém, em conformidade com ${ }^{26}$, os intérpretes da Libras não têm uma formação adequada para atuar na área de saúde, necessitando capacitar-se para atuar de modo mais profissional para que as pessoas surdas possam usufruir, sem constrangimento ou receio, na presença do profissional intérprete da língua.

Deste modo, percebe-se que a não realização de uma assistência adequada ao surdo não depende apenas dos interesses individuais de cada profissional, mas também da organização dos serviços ofertados na APS.

\section{Dados Qualitativos}

Os dados qualitativos oriundos da aplicação dos formulários aos profissionais de saúde da APS foram apresentados por meio das falas mais relevantes, de acordo com a categoria: dificuldades na assistência ao surdo na APS.

Há alguns entraves na assistência ao surdo que dificultam e às vezes até a impede de acontecer. Os profissionais precisam dar tudo de si para poder compreender o surdo e se fazer compreender. Esse esforço a mais precisa acontecer para que haja sentido e retorno positivo da assistência prestada.

A este respeito ${ }^{27}$, afirmam que a grande maioria dos profissionais tem dificuldade para realizar o atendimento, pois não se estão preparados para tal.

Nesta pesquisa foram encontrados resultados parecidos: 
É difícil demais atender um surdo! Eu não tenho experiência suficiente com esse público que me garanta fazer uma boa assistência para eles. Uma vez chegou um aqui e eu logo o encaminhei para a APAE. É essa a ordem que a gente tem! Francamente, eu não sei atender um paciente surdo. (E5).

Veio uma surda adolescente aqui sem a mãe dela. Foi complicado! Parece que ela estava com suspeita de gravidez e quis vir sozinha porque não queria que a família soubesse. Fiquei numa situação! Como perguntar a data da última menstruação? Estava com medo de desenhar uma vagina com sangue, e ela pensar que eu estava com desrespeito com ela. Sou homem! Estava com medo de apontar para o órgão genital dela e ser mal interpretado! A paciente ria de mim! Pareci um palhaço naquele dia! Quanto mais eu tentava manter uma comunicação parece que pior ficava! Eu sei que o pré-natal seria do mesmo jeito que é com outras mulheres, mas a falta da comunicação me esbarrou! Nem ela entendeu nada e nem eu! (E14).

Segundo estudos publicados, as dificuldades têm raízes na formação acadêmica dos profissionais, em questões pessoais, sociais e materiais ${ }^{21,5}$. Trata-se de um conjunto de situações que se aglomeram e impedem que o usuário surdo seja bem assistido pelos profissionais de saúde.

Os profissionais que afirmaram ter realizado algum atendimento ao cliente surdo, quando interrogados sobre como se comunicaram com ele, responderam.

O acompanhante informava tudo o que o surdo estava sentindo. A comunicação foi toda com o acompanhante. Ele é indispensável na consulta do surdo (M1)

A comunicação foi através de mímicas e desenhos. O acompanhante ajudou muito! (M5)

Tive a sorte de encontrar um surdo alfabetizado em português. Aí a nossa comunicação foi através da escrita. (M8)

Quando o surdo sabe ler, eu escrevo. Quando não sabe, tento falar bem próximo dele e um pouco alto. (E2)

A comunicação sempre se dá através de um acompanhante. É uma comunicação muito difícil, pois precisamos ficar gritando na tentativa de que o surdo ouça alguma coisa. Comunicação direta com o paciente nunca aconteceu. (E6) 
Foi complicado pelo fato de eu não entender o que ele queria falar, mas gesticulando a gente se entendeu. (E10)

O paciente sempre vem acompanhado e toda a comunicação acontece com o auxílio do acompanhante. (D7)

A menina fazia leitura labial! Isso facilitou demais a consulta. Eu falava e ela entendia! Difícil era na hora que ela queria falar, pois eu não entendia muito e ficava perdido! (D9)

Com muito esforço fui fazendo mímicas. Um atendimento muito difícil. (D10)

A dificuldade do atendimento foi enorme, pois eu tive que fazer gestos e mímicas, além de falar muito alto para que ele pudesse ouvir alguma coisa. (A/T 3)

A comunicação foi através da Língua de Sinais Brasileira. (A/T4)

A comunicação foi toda com a acompanhante. Com a surda mesmo eu não falei nada. (A/T16)

A comunicação foi através de gestos e também dos familiares que auxiliavam na conversa. (ACS1)

Eu falo bem alto pra ver se ela escuta alguma coisa! (ACS6)

A mãe dela é quem fala tudo! (ACS13)

Dentre os relatos dos profissionais mencionados acima, compreende-se que os profissionais necessitam da presença de algum acompanhante da família do surdo no momento durante o atendimento ao mesmo e que sem o acompanhante faz-se complicada a comunicação entre profissional e usuário.

Quanto a isso ${ }^{28}$, relatam que o surdo não tem oportunidade de se expressar e nem mesmo de expor as suas dúvidas na consulta, permanecendo a cargo do acompanhante a responsabilidade de explicar ao profissional os problemas de saúde que apresenta, sendo também a pessoa quem recebe as orientações. Além disso, a presença do acompanhante retira do surdo o direito da individualidade necessária para a sua exposição.

A esse respeito ${ }^{29}$, afirmam que muitas vezes passam por despercebidas a angústia e as dificuldades que só o próprio surdo sente, quando é transferida para os familiares a responsabilidade da comunicação. Por isso, o ideal é que todos os profissionais de saúde da APS sejam capacitados 
ISSN 2179-6750

para oferecer um atendimento humano ao surdo, atendimento esse que o próprio e mais interessado com os resultados dessa assistência possa falar de si e ser compreendido tal qual está expressando, quer seja através de gestos, de mímicas, sinais, expressões faciais ou ainda outra forma.

Sobre a comunicação ${ }^{26}$, declaram que esta é uma importante ferramenta de assistência ao paciente e afirmam que os profissionais de saúde precisam orientar verbalmente acerca do diagnóstico e tratamento e certificar-se de que o paciente conseguiu apreender todas as informações repassadas.

Ainda é possível identificar nas falas dos profissionais que existe o esforço de alguns em tentar manter uma comunicação com o surdo, mesmo que ele esteja com acompanhante. Nota-se que a comunicação não-verbal é uma poderosa aliada no atendimento ao surdo. Fazer mímicas, gesticular, desenhar, expressões faciais, falar pausadamente para ajudar na leitura labial e escrever, caso o surdo seja alfabetizado na língua portuguesa, auxiliam consideravelmente no momento de assistência ao surdo.

Em um estudo sobre a comunicação entre deficientes auditivos e profissionais de saúde, verificaram que poucas vezes são oferecidos treinamentos sobre língua de sinais para os profissionais de saúde e ainda referem que se acontecessem com frequência necessária, a consulta e demais atendimentos da pessoa surda seriam facilitados ${ }^{30}$.

Discutem a importância da capacitação em Libras para os profissionais de saúde e confirmam que o conhecimento da língua de sinais é um fator relevante no atendimento ao deficiente auditivo, por isso sugerem que todos os profissionais da APS devem ser capacitados ${ }^{24}$.

\section{Considerações Finais}

A surdez, quando total, impede que o surdo desenvolva a fala, e por isso, é colocado às margens da sociedade, uma vez que não é capaz de se comunicar com os ouvintes através da língua falada. Dessa forma, a pessoa surda não consegue manter uma comunicação satisfatória com os ouvintes à sua volta.

Neste estudo ouviram-se 99 profissionais atuantes da APS da cidade de Caxias/MA, dentre eles, médicos, enfermeiros, cirurgiões dentistas, auxiliares/técnicos de enfermagem e ACS. Todos opinaram sobre a temática e os questionamentos levantados com esta pesquisa.

Identificou-se que 95,9\% dos profissionais não dominam a Libras, e por este motivo, não a utilizam no atendimento às pessoas surdas, buscando então, outras formas de manter contato com as últimas. 
ISSN 2179-6750

As principais dificuldades referidas pelos profissionais no atendimento aos surdos foram: a comunicação, sendo a principal delas; falta de conhecimento sobre a Libras; a falta de capacitação em Libras e inexistência de recursos que possam auxiliá-los no diálogo com os usuários. Mas além desses, observou-se a falta de comprometimento e interesse da parte dos profissionais para com a população surda do município de Caxias.

Os profissionais sugerem que lhes sejam oferecidas capacitações em Libras para que possam melhorar suas condutas no atendimento às pessoas surdas; recursos visuais que auxiliem na interação com o usuário; cartilha com as expressões mais utilizadas na consulta em português com seus respectivos sinais em Libras e, ainda que a coordenação dos serviços da APS faça contratações de intérpretes que possam ser solicitados sempre que houver consulta de usuários surdos na UBS.

Quanto à existência de recursos físicos, organizacionais e/ou materiais que pudessem auxiliar os profissionais de saúde a assistir ao paciente surdo na APS, verificou-se que não há recurso algum. De acordo com os profissionais, a existência desses materiais seria primordial para uma melhor realização da assistência a esse público, uma vez que ajudariam a vencer as barreiras impostas pela dificuldade de manter a comunicação entre profissionais ouvinte e clientes surdos.

Sugere-se que os responsáveis pelos serviços de APS organizem e ofereçam capacitações em Libras para os profissionais, além de materiais visuais que possam auxiliá-los; que os trabalhadores de saúde busquem fazer curso de Libras, mesmo que de maneira espontânea e que vejam o surdo como uma pessoa que tem necessidades que vão além de sua incapacidade de ouvir, tratando-o humanamente, com respeito e atenção.

\section{Referências}

1. Redondo MC, Carvalho JM. Deficiência auditiva. Cadernos da TV Escola Brasília: MEC, Secretaria de Educação a Distância; 2000.

2. Brasil. Ministério da Saúde. Conade - Conselho Nacional dos Direitos da Pessoa Portadora de Deficiência. Decreto nº 5.296, de 02/12/04. Brasília: Ministério da Saúde; 2004.

3. Instituto Brasileiro de Geografia e Estatística. Síntese dos indicadores sociais. 2010. Disponível em: <http://www.ibge.gov.br/indicadores.php>. Acesso em 09 de agosto de 2014.

4. Carvalho-Freitas MN, Marques AL. Formas de ver as pessoas com deficiência: um estudo empírico do construto de concepções de deficiência em situações de trabalho. Rev. Adm. Mackenzie 2010; 11(3):100-129.

5. Chaveiro, N, Barbosa MA, Porto CC, Munari DB, Medeiros M, Duarte SBR. Atendimento à 202 
ISSN 2179-6750

pessoa surda que utiliza a língua de sinais, na perspectiva do profissional da saúde. Cogitare Enferm 2010; 15(4): 639-645.

6. Brasil. Ministério da Saúde. Lei n. 10.436, de 24 de abril de 2002. Dispõe sobre a Língua Brasileira de Sinais e dá outras providências. Brasília: Ministério da Saúde; 2002.

7. Grossi Junior RU, Santos DAS. Utilização da Língua Brasileira de Sinais no atendimento aos surdos. Rev. Virt. de Cultura surda e diversidade 2009;5(4): 187-198.

8. Ohara ECC, Saito RXS. Saúde da Família: considerações teóricas e aplicabilidade. 2. ed. São Paulo: Martinari; 2010.

9. Milbrath VM, Soares DC, Cecagno D, Amestoy SC, Siqueira HCH . Inserção social da criança portadora de necessidades especiais: a perspectiva materna. Cogitare Enferm 2009; 14(2): 311-319.

10. Conceito de avaliação por triangulação de métodos. In: Minayo MCS, Assis SG, Souza ER. Avaliação por triangulação de métodos: Abordagem de Programas Sociais. Rio de Janeiro: Fiocruz; 2005.

11. Deslandes SF, Assis SG. Abordagens quantitativa e qualitativa em saúde: o dialogo das diferenças. In: Minayo MCS, Deslandes SF (Org.). Caminhos do pensamento: epistemologia e método. Rio de Janeiro: Fiocruz; 2002.

12. Minayo MCS. Pesquisa avaliativa por triangulação de métodos. In: Bosi MLM, Mercado FJ. Avaliação qualitativa de programas de saúde: enfoques emergentes. Petrópolis, RJ: Vozes; 2006a.

13. Instituto Brasileiro de Geografia e Estatística. Cidades. [s.l.:s.n.], 2012. Disponível em: < http:// www.ibge.gov.br/cidades >. Acesso em: 02 de agosto de 2014.

14. Lakatos EM, Marconi MA. Fundamentos de metodologia científica. São Paulo: Atlas; 1991.

15. Bardin L. Análise de conteúdo. [Trad. Luiz Antero Reto e Augusto Pinheiro]. São Paulo: Edições 70; 1997.

16. Gomes R. Análise e interpretação de dados de pesquisa qualitativa. In: Minayo MCS, Deslandes SF, Gomes R. Pesquisa social: teoria, método e criatividade. 29. ed. Petrópolis, RJ: Vozes; 2010.

17. Levino DA, Souza EB, Cardoso PC, Silva AC, Carvalho AETM. Libras na graduação médica: o despertar para uma nova língua. Rev. bras. educ. med. [online] 2013; 37(2): 291297.

18. Cardoso AHA, Rodrigues KG, Bachion MM. Percepção da pessoa com surdez severa e/ou profunda acerca do processo de comunicação durante seu atendimento de saúde. Rev. Lat. 
ISSN 2179-6750

Am. Enfermagem 2006;14(4): 332-343.

19. Silva MJP. Comunicação tem remédio: a comunicação nas relações interpessoais em saúde. 4.ed. São Paulo: Loyola; 2006.

20. Freitas DA, Antunes SLNO, Caldeira AP, Silveira MD. Odontologia inclusiva. Percepções de indivíduos surdos sobre a comunicação com profissionais da odontologia. Rev. Digital 2011; 16(155): 156-167.

21. Trecossi MO, Ortigara EPF. Importância e eficácia das consultas de enfermagem ao paciente surdo. Rev enferm. 2013; 9(9): 60-69.

22. Brites LS, Souza APR, Lessa H. Fonoaudiólogo e agente comunitário de saúde: uma experiência educativa. Rev Soc Bras Fonoaudiol. 2008;13(3):258-266.

23. Sugário MPVG, Botelho MPJ. Uma proposta para melhorar a comunicação entre profissionais de odontologia e o paciente surdo. Anais Eletrônico; 2012.

24. Souza MT, Porrozzi R. Ensino de Libras para os Profissionais de Saúde: Uma Necessidade Premente. Rev. Práxis 2009; I(2): 87-98.

25. Damasceno RHF et al. Cartilha de Libras: sinais de inclusão. Alfenas: Minas Gerais. 2010.

26. Chaveiro N, Barbosa MA, Porto CC. Revisão de literatura sobre o atendimento ao paciente surdo pelos profissionais da saúde. Rev. Esc. Enferm. 2008; 42(3):578-83.

27. França EG. Atenção à saúde do surdo na perspectiva do profissional de saúde. 2011.82 f. Dissertação. (Mestrado). Campina Grande-PB: Universidade Estadual da Paraíba; 2011.

28. Santos EM, Shiratori K. As necessidades de saúde no mundo do silêncio: um diálogo com os surdos. Revista Eletrônica de Enfermagem 2004; 06(01): 222-233.

29. Gomes V, Correa MS, Manfrin RM, Silva JRS. Vivência do enfermeiro ao cuidar surdos e/ou portadores de deficiência auditiva. Enferm. Glob. 2009; 1(17): 20-30.

30. Queiroz APO Rocha, ESN, Páscoa FRB, Lima FET. A comunicação entre deficientes auditivos e profissionais de saúde - uma revisão bibliográfica. In: Congresso Brasileiro De Enfermagem, 61, Fortaleza. Anais. Fortaleza: [s.n.]: 123-126; 2009. 